\title{
SISTEM WAYFINDING MALL DI SEMARANG
}

\author{
Brigita Theora Mega Kusumasari*), Bangun IR Harsritanto \\ *) Corresponding author email : theoramega@gmail.com
}

Departemen Arsitektur, Fakultas Teknik, Universitas Diponegoro - Indonesia

\author{
Article info \\ MODUL vol 19 no 1, issues period 2019 \\ Doi : $\quad: 10.14710 / \mathrm{mdl} \cdot 19.1 .2019 .10-14$ \\ Received : 7th december 2018 \\ Revised : :21st january 2019 \\ Accepted : 1st may 2019
}

\begin{abstract}
Shopping mall merupakan salah satu bangunan komersil yang sudah menjadi gaya hidup bagi sebagian besar masyarakat perkotaan. Masyarakat pergi mengunjungi shopping mall untuk memenuhi memenuhi kebutuhan seperti berbelanja, maupun sekedar berekreasi dan mencari hiburan. Sebagai bangunan umum yang menawarkan berbagai fasilitas dan ramai dikunjungi oleh masyarakat, shopping mall perlu dilengkapi dengan sistem wayfinding yang baik supaya pengguna bangunan tidak mengalami disorientasi. Metode penelitian yang digunakan dalam penyusunan laporan ini adalah metode deskriptif, dokumentatif, dan komparatif dimana penyusunan dilakukan dengan mengumpulkan data, menjelaskan, dan menjabarkan terhadap informasi terkait bagaimana pengaruh bahan lantai serta pemilihan bahan lantai yang baik dan murah diaplikasikan pada jalur pedestrian bagi kenyamanan dan keamanan pengguna. Wayfinding adalah kemampuan seseorang untuk bernavigasi dalam suatu lingkungan. Sistem wayfinding adalah fasilitas yang memiliki fungsi memberikan kemudahan bagi pengguna dalam bernavigasi. Tujuan dari penelitian ini adalah untuk menjelaskan dan mengevaluasi sistem wayfinding mall di Semarang.Hasil yang didapat adalah desain mall di Semarang cukup efektif untuk membantu wayfinding penggunannya.
\end{abstract}

Keywords: wayfinding; mall; shopping;Semarang

\section{PENDAHULUAN}

Kota Semarang sebagai salah satu wilayah perkotaan di Indonesia akan selalu mengalami perkembangan, salah satunya adalah gaya hidup BT Mega K, Bangun IR Harsritanto masyarakat. Shopping mall merupakan salah satu bangunan komersil yang sudah menjadi gaya hidup bagi sebagian besar masyarakat perkotaan. Masyarakat pergi mengunjungi shopping mall untuk memenuhi memenuhi kebutuhan seperti berbelanja, maupun sekedar berekreasi dan mencari hiburan. Sebagai bangunan umum yang menawarkan berbagai fasilitas dan ramai dikunjungi oleh masyarakat, shopping mall perlu dilengkapi dengan sistem wayfinding yang baik supaya pengguna bangunan tidak mengalami disorientasi Menurut Gibson (2009), desain wayfinding memberikan pedoman dan bertujuan untuk membantu pengguna merasakan kemudahan disekitar. Sistem wayfinding yang baik menyuguhkan penanda dan informasi yang bersifat eksplisit (tegas) serta memiliki simbol dan landmark yang memiliki makna secara implisit (tersirat), kedua hal tersebut secara bersamaan menyampaikan maksud secara langsung dan tepat. Dalam sebuah ruang atau tempat seorang pengguna harus menentukan tujuan,kemudian langkah-langkah untuk mencapai tujuan ini akan ditentukan oleh pengguna berdasarkan informasi yang tersedia, dan dengan mudah terlihat Penelitian yang dilakukan oleh penulis merupakan identifikasi terhadap efektifitas wayfinding dengan menggunakan empat strategi berupa: district, streets, connector, dan landmark, dan mengidentifikasi signage dan pengaruhnya terhadap efektifitas wayfinding dalam bangunan mall. Menurut Gibson (2009), empat strategi atau pendekatan tersebut merupakan konsep perancangan perkotaan yang dan kemudian digunakan juga sebagai strategi sistem wayfinding dalam suatu bangunan atau lingkungan, yang lebih lanjut digunakan oleh para desainer wayfinding untuk merancangan sistem signage. Sedangkan signage menurut O'Neill (1991) merupakan sesuatu yang berfungsi untuk meningkatkan efektifitas wayfinding, terutama di dalam bangunan yang memiliki konfigurasi yang kompleks.

\section{METODE PENELITIAN}

Metode penelitian yang digunakan dalam penyusunan laporan ini adalah metode deskriptif, dokumentatif, dan komparatif dimana penyusunan 
dilakukan dengan mengumpulkan data, menjelaskan, dan menjabarkan terhadap informasi terkait bagaimana pengaruh bahan lantai serta pemilihan bahan lantai yang baik dan murah diaplikasikan pada jalur pedestrian bagi kenyamanan dan keamanan pengguna.

Langkah-langkah yang diambil dalam pengumpulan data adalah :

\section{a. Metode Deskriptif}

Metode deskriptif dilakukan dengan pengumpulan data yang berasal dari studi pustaka/literatur, data dari instansi terkait, observasi lapangan, serta browsing internet.

b. Metode Dokumentatif

Metode dokumentatif dilakukan dengan mendokumentasikan data yang menjadi bahan penyusunan dalam penulisan laporan dengan cara memperoleh gambar visual dari foto-foto yang dihasilkan.

c. Metode Komparatif

Data yang terkumpul kemudian diidentifikasi dan dianalisis serta dibandingkan untuk memperoleh gambaran yang cukup lengkap mengenai karakteristik dan kondisi yang ada

Waktu Penelitian

1. Tahap Pertama

Waktu : 23 Oktober 2017

Tempat : Paragon City Mall Semarang

2. Tahap Kedua

Waktu : 25 Oktober 2017

Tempat : DP Mall Semarang

3. Tahap Ketiga

Waktu : 6 November 2017

Tempat : Pasaraya Sri Ratu Semarang

\section{PEMBAHASAN}

Menurut Rianty, wayfinding adalah suatu proses manusia bernavigasi dan mengorientasikan diri dalam ruang fisik. Proses tersebut mencakup usaha manusia memperoleh, menetapkan, dan menemukan serangkaian jalur yang akan dilalui untuk berangkat dari satu tempat menuju tempat lain.

Sistem wayfinding memberikan pedoman dan mempermudah seseorang dalam suatu lingkungan (Gibson, 2009) Menurut Gibson (2009) wayfinding merupakan sistem yang mendasari perencangan signange. Sedangkan signage menurut O’Neill adalah sesuatu yang dibuat untuk meningkatkan efisiensi wayfinding, terutama dalam bangunan yang memiliki konfigurasi yang kompleks. Faktor kompleksitas bangunan berpengaruh terhadap keefektifan wayfinding dalam suatu lingkungan atau bangunan. Semakin kompleks suatu bangunan atau lingkungan, maka semakin tidak efektif wayfinding dalam bangunan atau lingkungan tersebut. Sehingga, perlu menambahkan signage agar tidak menyebabkan disorientasi bagi pengguna yang berada dalam bangunan atau lingkungan tersebut.

\section{Strategi Wayfinding}

Menurut Gibson (2009), dalam perspektif seorang wayfinding desainer, menjelaskan bahwa dalam proses perancangan wayfinding terdapat empat pendekatan atau strategi yang digunakan yaitu: district, street, connector, dan landmarks. Keempat strategi tesebut bermula dari konsep perancangan kota. Berikut merupakan penjelasan mengenai keempat pendekatan tersebut:

a. District : merupakan zona-zona dalam suatu bangunan/lingkungan

b. Street : merupakan koridor atau pathway yang menghubungkan antar ruang

c. Connector : diartikan sebagai pathway terbesar yang menghubungkan ruang atau tujuan dalam satu hubungan atau garis

d. Landmarks : merupakan titik kumpul paling besar / titik yang mudah ditemui /titik terbesar dan menonjol

Strategi tersebut pada intinya dapat diartikan sebagai "mental map" yang terekam dalam pikiran pengguna bangunan "Mental map" tersebut dapat digambarkan sebagai bentuk diagramatik mengenai suatu kompleks yang digambarkan secara sederhana, mudah, dan cepat untuk dipahami. Kemudian pandangan ini digunakan oleh para desainer wayfinding untuk merancang sistem penanda atau yang selanjutnya disebut sebagai signage. Signage memiliki fungsi mempermudah pengguna untuk bernavigasi. Pola bernavigasi ini juga mengacu kepada strategi dalam wayfinding, dan berikut merupakan pola bernavigasi dasar yang digunakan oleh pengguna:

a. Berpindah dari satu district ke district lain

b. Berjalan disepanjang koridor

c. Menentukan pilihan lanjut saat berada dalam landmarks

Dengan penjelasan mengenai strategi wayfinding diatas, dapat disimpulkan bahwa wayfinding harus mampu mengkomunikasikan penanda (sign) baik yang berupa informasi grafik, maupun rasa keruangan dalam konteks arsitektural yang diberikan kepada pengguna yang pada penjelasan sebelumnya disebutkan sebagai "mental map". Baik signage maupun "mental map" ini harus diterima dengan mudah oleh pengguna mulai dari awal perjalanan di titik kedatangan, sepanjang perjalanan, dan ketika pengguna sampai pada decisision poin (titik dimana pengguna memutuskan untuk memilih tujuan selanjutnya), hingga mengakhiri perjalan dengan menuju ke titik keluar.

\section{Strategi Signage \\ Wayfinding merupakan sistem yang menghubungkan bermacam-macam orang secara}


bersamaan. Dalam suatu ruang publik yang sama terdapat kemungkinan akan didatangi oleh berbagai macam orang, yang bisa saja memiliki bermacam bahasa dan dalam ruang public yang sama itu juga terdapat kemungkinan satu orang dengan yang lain memiliki berbagai macam tujuan. Sistem wayfinding menghubungkan berbagai macam keadaan tersebut dengan memberikan panduan kepada para pengguna melaui ruang yang sama dengan menggunakan sistem komunikasi tunggal.

Agar wayfinding dapat bekerja dengan efisien sekalipun di ruang atau bangunan yang memiliki kompleksitas tinggi, maka perlu di dukung dengan signage. Signage berasal dari kata "sign" yang secara etimologi memiliki arti "tanda, pertanda, isyarat". Sedangkan signage memiliki pengertian sebagai sign secara kolektif. Tiap sign dalam signage system memiliki fungsi dan menyajikan konten spesifik berupa pesan atau informasi, yang dapat berupa simbol, gambar, atau kata-kata.

Lokasi peletakan sign ditentukan setelah dilakukan analisis terhadap titik kedatangan, titik keberangkatan, decisison point, pola sirkulasi, dan juga peluang penandaan. Tidak hanya lokasi peletakan, para desainer wayfinding perlu mengetahui juga jenis sign apa yang akan diletakan pada suatu lokasi. Berikut merupakan jenis-jenis sign yang digunakan dalam wayfinding :
1. Identification Sign
2. Directional Sign
3. Orientation Sign
4. Regulatory Sign

\section{Pasar Raya Sriratu}

Pasaraya Sri Ratu terletak di Jalan Pemuda Nomor 29-33, Kecamatan Semarang Tengah, Kota Semarang dengan keterangan tersebut di gambar 1 .

Pasaraya Sri Ratu Semarang memiliki batas-batas sebagai berikut:Batas Timur : Pertokoan, Batas Selatan : Jalan Pemuda, Batas Barat : Jalan Gendingan, Batas Utara : Jalan Imam Bonjol.

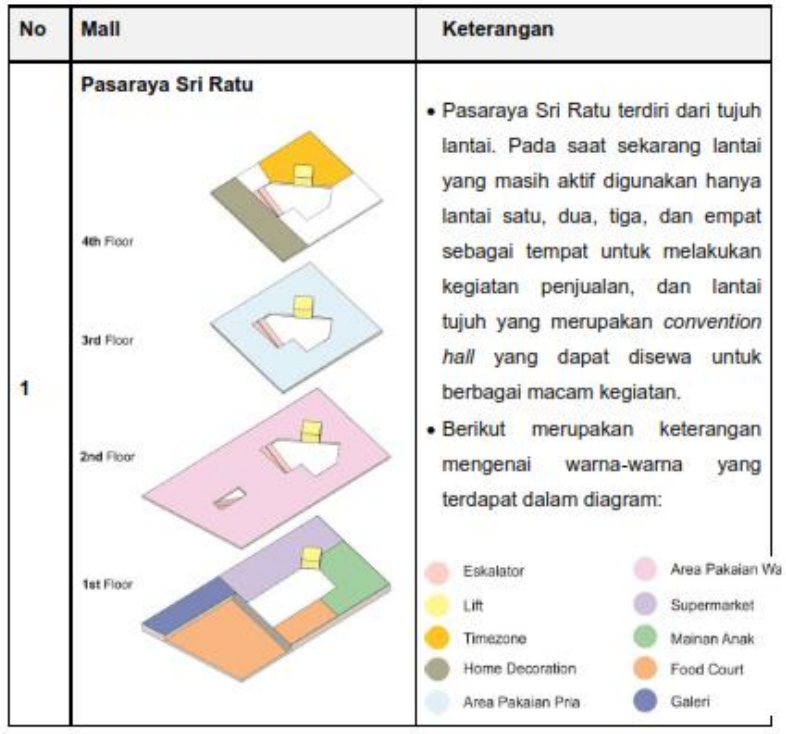

gambar 1. Kondisi Sri Ratu

\section{Paragon Mall}

Paragon City Mall terletak di Jalan Pemuda Nomor 118, Kelurahan Sekayu, Kecamatan Semarang Tengah, Kota Semarang dengan kondisi tersebut pada gambar 2. Paragon City Mall memiliki batas-batas wilayah sebagai berikut: Batas Timur : PT Pertamina Persero Batas Selatan : Permukiman Warga, Batas Barat : Jalan Sekayu, Batas Utara : Jalan Pemuda

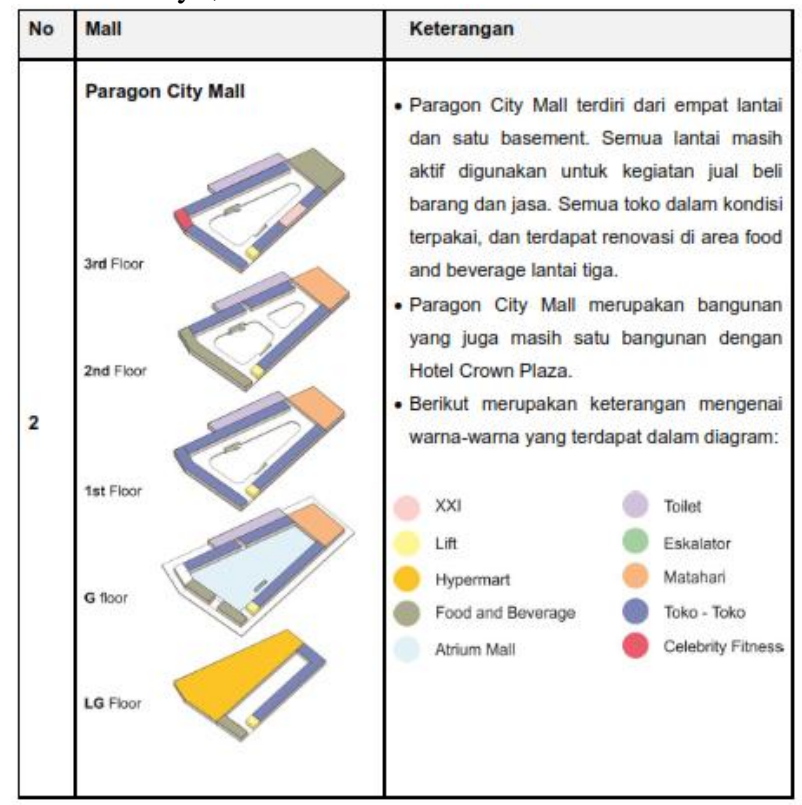

gambar 2. Kondisi Paragon City Mall

\section{Duta Pertiwi Mall}

DP Mall Semarang terletak di Jalan Pemuda Nomor 150, Kelurahan Sekayu, Kecamatan Semarang Tengah, Kota Semarang. DP Mall Semarang memiliki batas-batas wilayah sebagai berikut: Batas Timur : Balai 
Kota Semarang Batas Selatan : Jalan Inspeksi, Batas Barat : Maybank dan Tanah Kosong, Batas Utara : Jalan Pemuda

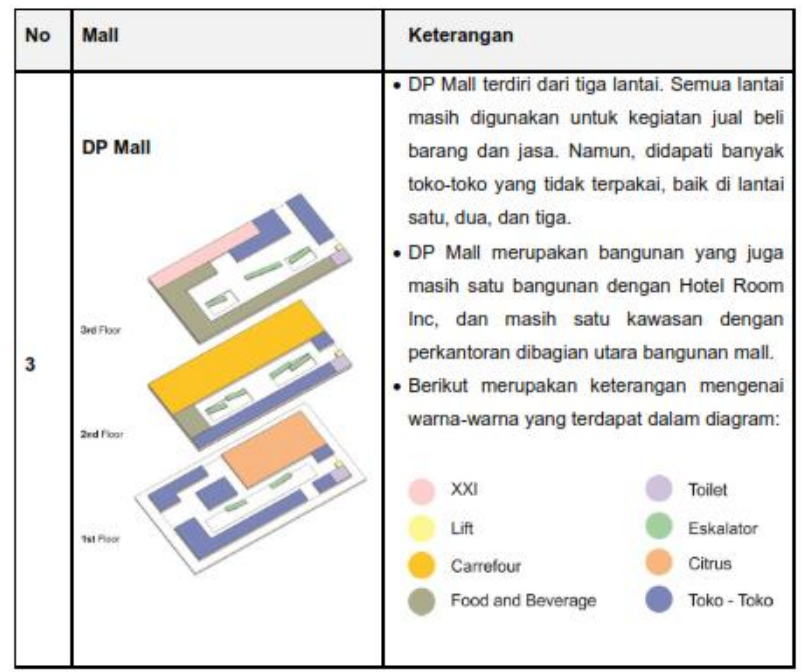

gambar 3. Kondisi Duta Pertiwi Mall

\section{Wayfinding Sriratu}

Sampai dengan pembahasan ini dapat disimpulkan bahwa wayfinding pada bangunan Pasaraya Sri Ratu ini kurang efektif jika ditinjau menggunakan strategi: district, street, connector, dan landmarks. Kurang efektifnya wayfinding ini disebabkan oleh kompleksitas bangunan, namun keefektifan wayfinding ini dapat diatasi dengan menambahkan signage. Pada tabel selanjutnya penulis akan membahas mengenai sistem signage pada bangunan Pasaraya Sri Ratu, agar dapat mengetahui apakah sistem signage pada bangunan ini sudah mampu membantu meningkatkan efektifitas wayfinding.

Berikut gambar 4, merupakan diagram posisi signage pada bangunan Pasaraya Sri Ratu Semarang, disertai penjelasan mengenai jenis signage dan maksud dari signage tersebut:

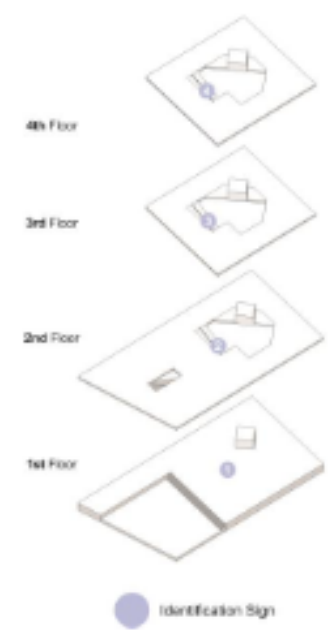

gambar 4. Posisi Sign di Sri Ratu
Pada bangunan Pasaraya Sri Ratu posisi signage hanya berada di eskalator, dan signage tersebut hanya terdiri dari satu jenis sign, yaitu identification sign. Tidak terdapat directional sign pada decision points. Dari temuan tersebut dapat disimpulkan bahwa wayfinding dalam bangunan Pasaraya Sri Ratu Semarang secara keseluruhan masih belum efektif

\section{Wayfinding Paragon Mall}

Pada analisi wayfinding bangunan Paragon City Mall dengan menggunakan strategi: district, streets, connection, dan district ini dapat disimpulkan bahwa wayfinding dalam bangunan sudah baik. Keempat strategi tersebut mudah dipahami oleh pengunjung. Pada analisis dengan indikator streets terdapat titik percabangan yang dinamakan decision points. Pada titik tersebut seharusnya terdapat directional sign, agar pengunjung tidak mengalami kebingungan. Pada pembahasan dibawah penulis akan menjelaskan mengenai sistem signage pada bangunan Paragon City Mall.

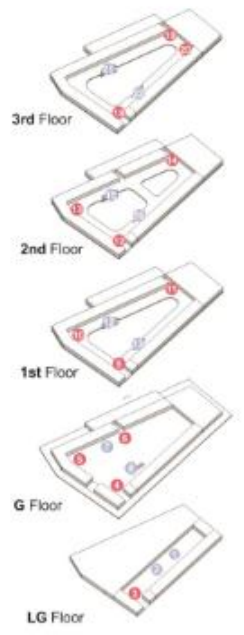

gambar 5. Posisi Sign Paragon City Mall

Dapat dilihat pada posisi sign di gambar 5 atas bahwa titik-titik selain yang dibuktikan melalui sampel tersebut, diantaranya merupakan decision points. Sehingga sistem signage dapat dikatakan sudah meningkatkan efektifitas wayfinding dalam bangunan. Dari penjelasan mengenai sampel signage pada bangunan Paragon Mall tersebut dapat disimpulkan bahwa sistem signage berhasil meningkatkan efektifitas wayfinding yang sebelumnya dianalisis menggunakan strategi: district, streets, connection, dan landmarks. Sehingga secara keseluruhan dapat dikatakan bahwa sistem wayfinding pada bangunan Paragon City Mall sudah efektif 


\section{Wayfinding DP Mall}

Berikut merupakan diagram posisi sign dalam bangunan DP Mall. Karena titik-titik sign pada diagram dibawah sudah memenuhi decision points, maka penulis akan mengambil sampel satu dari tiga lantai untuk mengidentifikasi jenis, dan informasi yang disampaikan dalam sign (lihat gambar 6). Penulis akan menggunakan lantai satu sebagai sampel.

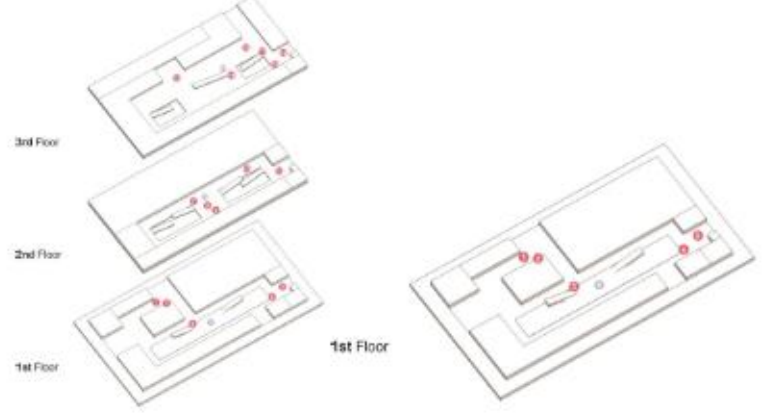

gambar 6. Posisi Sign Duta Pertiwi Mall

Dari analisi empat strategi wayfinding : districts, streets, conncetion, dan landmarks dapat diketahui bahwa kondisi koridor pada lantai satu dan landmark yang berada di lantai tiga mengakibatkan wayfinding pada bangunan DP Mall ini kurang efektif. Pada pembahasan selanjutnya akan dilakukan analisis terhadap entrance dan exit points, serta decisision points dan dikomparasi dengan sistem signage yang ada dalam bangunan DP Mall.

Dari data, analisa serta pembahasan diatas, dapat disimpulkan efektifitas masing-masing mall dan perbandingannya dalam tabel berikut:

Tabel 1. Tabel Perbandingan 3 Mall di Semarang

\begin{tabular}{|c|c|c|c|c|c|c|c|c|c|}
\hline \multirow{3}{*}{ Indikator } & \multicolumn{3}{|c|}{ Pasaraya Sri Ratu } & \multicolumn{3}{|c|}{ Paragon City Mall } & \multicolumn{3}{|c|}{ DP Mall } \\
\hline & Efektif & Cukup & Kurang & Efektif & Cukup & Kurang & Efektif & Cukup & Kurang \\
\hline & \multicolumn{3}{|c|}{$\frac{\text { Natal }}{2}$} & \multicolumn{3}{|c|}{$\frac{\text { Nital }}{2}$} & \multicolumn{3}{|c|}{$\frac{\text { Natal }}{2}$} \\
\hline District & & & $\mathrm{v}$ & & $\mathrm{v}$ & & $\mathrm{v}$ & & \\
\hline Street & & & $\mathrm{v}$ & $\mathrm{v}$ & & & & & $\mathrm{v}$ \\
\hline Connector & & & $\mathrm{v}$ & & $\mathrm{v}$ & & & $\mathrm{v}$ & \\
\hline Landmark & & & $\mathrm{v}$ & $\mathrm{v}$ & & & & & $\mathrm{v}$ \\
\hline Signage & & & $\mathrm{v}$ & $\mathrm{v}$ & & & v & & \\
\hline Total Nilai & \multicolumn{3}{|c|}{$5 / 15$} & \multicolumn{3}{|c|}{$11 / 15$} & \multicolumn{3}{|c|}{$10 / 15$} \\
\hline
\end{tabular}

Dari tabel 1 tersebut dapat disimpulkan bahwa Mall di Jalan Pemuda yang memiliki wayfinding yang paling efektif adalah Paragon City Mall.

\section{KESIMPULAN}

Wayfinding adalah kemampuan seseorang untuk bernavigasi dalam suatu lingkungan. Sistem wayfinding adalah fasilitas yang memiliki fungsi memberikan kemudahan bagi pengguna dalam bernavigasi. Sistem wayfinding yang baik dapat ditinjau melalui empat strategi, yaitu: District, Streets, Connection, dan Landmarks. Jika pengguna dengan mudah membayangkan keempat strategi tersebut dalam suatu diagram "mind map", ketika berada dalam suatu bangunan atau lingkungan maka dapat dikatakan bahwa bangunan atau lingkungan tersebut memiliki sistem wayfinding yang efektif.

Bangunan atau lingkungan yang memiliki kompleksitas tinggi akan mengakibatkan wayfinding semakin tidak efektif. Sistem signage dapat mendukung efektifitas wayfinding dalam suatu bangunan atau lingkungan yang kompleks. Dalam penelitian ini, didapatkan hasil seberapa efektif wayfinding dalam bangunan mall dengan urutan dari yang paling efektif sebagai berikut: [1] Paragon City Mall; [2] DP Mall; [3] Sri Ratu. Dapat disimpulkan bahwa mall di Jalan Pemuda yang memiliki sistem wayfinding paling efektif adalah Paragon City Mall. Paragon City Mall dikatakan paling efektif karena memiliki Streets, Landmarks, dan Signage yang efektif, dan Landmark serta Connector yang tidak efektif terbukti efektifitasnya meningkat karena didukung oleh sistem signage.

\section{DAFTAR PUSTAKA}

Gibson, David. 2009. The Wayfinding Handbook, Information Design for Public Places. NewYork: Princeton Architectural Press

O’Neill, Michael J. 1991. Effects of Signage and Floor Plan Configuration on Wayfinding

Accuracy. http://journals.sagepub.com/ (6 November 2017)

Rianty, Mirradewi. Tanpa Tahun. Strategi Manusia dalam Wayfinding. www.academia.edu (6 November 2017) 